\title{
The Impact of Planning on the Quality of Educational Programs at Al- Balqa' Applied University
}

\author{
Hamdan Salim Alawamleh ${ }^{1}$, Ahmed Bdah ${ }^{2} \&$ Nidal Alahmad ${ }^{2}$ \\ ${ }^{1}$ Faculty of Business, AL-Balqaa Applied University, Al-salt, Jordan \\ ${ }^{2}$ Princess Alia University College, AL-Balqaa Applied University, Amman, Jordan \\ Correspondence: Dr. Hamdan Salim Alawamleh, Faculty of Business, AL-Balqaa Applied University, Al-salt, \\ Jordan. Tel: 962-79-909-7076. E-mail: h.alawamlah@yahoo.com
}

Received: July 29, 2013

Accepted: August 12, 2013

Online Published: September 6, 2013

doi:10.5430/ijba.v4n5p38

URL: http://dx.doi.org/10.5430/ijba.v4n5p38

\begin{abstract}
The aim of the study is to investigate the impact of planning on the quality of educational programs at Al- Balqa' Applied University from the perspective of the faculty members and heads of academic departments and deans and their assistants and their deputies in order to detect whether if there is a significance statistical differences due to the variables (Sex, qualification, years of experience, the functional level), after the statement of the correlation between the variables of the study, the researchers used the descriptive analytical approach through the development of an instrument of a study showing the impact of the reality of planning on the quality of educational programs at the AlBalqa' Applied University, the instrument include included the (26) paragraph that have been checked for validity and reliability, (248) distribute questionnaire to members of the study sample. The results of the study show that the presence of correlation significant statistically correlation between planning, effectiveness and quality of educational programs at the Al- Balqa' Applied University, the study recommended the deployment of a culture of planning and the support of strategic management at the university to develop expressive ambitious plans for its vision to achieve its mission as a participatory process between everyone to work as one team, which reflected positively on the quality of educational programs offered by the university.
\end{abstract}

Keywords: Al- Balqa' Applied University, educational programs, planning

\section{Introduction}

The process of the university education planning and evaluation became a necessity in the current societies because of the development that it brings it to them. Planning is a continuous progressively process in all educational institution to cope with the huge technological development, planning became the focal point to face all internal and an external challenges that the educational institution most adapt with it, all educational programs must be compatible with internal and external environments. The academic accreditation decides the quality of the high education institutions, the academic accreditation play the seiner role in the development of the academic insinuations especially in the Arab world which composed of many developed countries.

In the context of global competition, which is increasing day after day at the programs of the accreditation, mutual and joint institutions of higher education universally recognized, the institutions of higher education in the Arab world higher education must be able to tackle the challenges facing it, the review of radical and deep policy, regulations, laws, legislation, plans, programs and curricula, as well as the adoption of scientific methodology in planning, monitoring and control, enable Arab world higher education to fulfill its obligations towards future generations by providing them with competencies and skills required by the plans of social and economic development within the educational programs of the universities.

One of the most important aspects of the knowledge revolution and information in which we live currently, is the transformation of modern society from the industrial society to a knowledge society, and the emergence of what is known knowledge economy, which imposes a college education need to reconsider the objectives, where it became necessary to start the goals of the argument that supply creates demand, and not vice versa, as applicable currently, particularly in developing countries, as well as globalization, and the resulting phenomenon of global competitiveness, imposed on universities need to review their educational programs on a regular basis, and check the 
quality of their output, and in particular the level of its graduates, as the attention-quality output of academic programs is considered a mainstay achieving economic and social development of any advanced country was or even developing country, and this is the motivation behind the need for change and development and the pursuit of creating standards adoption of public and private, within the standards quality education makes educational institutions a comprehensive and competitive, continuity and excellence, such challenges include all developed and developing countries and emerging countries alike, so it became necessary to concentrate the focus of attention on the development of higher education through the planning processes and effectiveness to include philosophy, mission and strategies and outputs in harmony with recent developments and data (Wilkinson \& Toylor, 2007).

In order to achieve reliability in higher education a set of standards must be available in educational institutions as referred to by the National Center for Quality Assurance and the adoption of educational institutions (2012) so that they can reach the level of quality that enable them to achieve competitive advantages with their counterparts, and then the obligation to apply the concepts of quality will qualify universities which seeks to develop and apply for accreditation desired, and in particular with the pursuit of several Arab universities in recent times to establish partnerships and strategic alliances with universities in developed countries, including makings for academic Accreditation required by international institutions, regional or local. Although the quality concepts to be applied in the field of higher education, apply to the first module which is the university, it should also apply to other units in the lower level such as colleges passed sections and subsequent academic programs, educational, and with the certainty that quality integrated process, they should start and continue at all levels, in parallel, but it is important at this time to start educational programs and immediately in the application of the concepts of quality, so as a first core of any scientific institution, so if there is a genuine desire to develop a product that provides the university community, where society no longer bear the presence of not efficient academic institutions because it means different waste of resources.

Taylor and Cleland (2004) mentioned that the planning is the major step and the starting point in the developing and improvement of the educational organizations, And thus upgrading their quality, it is important now to focus these institutions to achieve excellence, quality and quality assurance, and should include the concept of excellence and quality all the functions of higher education and activities of teaching and scientific research, and community service, both at the university level, college or academic program, and the pursuit of excellence in this sense will lead to the promotion of the competent authorities, and therefore the recognition of degrees and certificates awarded by, and I have become clear orientation towards quality tertiary education institutions and programs has become not an option it does not inevitable, achieving the highest levels of quality in higher education and its institutions is a response to a logical and natural for many of the changes unprecedented faced by universities (Qowi,2008).

From here the importance of the stems to spreading the culture of quality and implementation of its programs in field of higher education to all of its units, and thereby helping to achieve the driving required to pay the higher education system, and effectively in the direction of its objectives and mission entrusted to it, by the community and the parties many relevant.

As the dissemination of a culture of quality and application programs as indicated Anderson (2006) means the involvement of every individual and management, scientific integrity and student and faculty member to become part of those programs.

Looking at the quality of university education in general, and on the undergraduate level, in particular, the recent trends in the measurement and management of quality work to avoid a narrow outlook and work on measuring the outputs of university education of the availability of properties directional and cognitive and behavioral graduates, but also extends measure the quality of service to the quality of the elements of the educational process at the level of academic programs for undergraduate, and here are the main driver of the current study and identify the impact of the reality of planning on the quality of educational programs in Al- Balqa' Applied University.

\section{Problem}

Currently many problems facing higher education systems; It became a lot of college graduates are not able to take responsibility, in addition to the lack of willingness to be active citizens in the community, therefore it was necessary to develop education and recitation by professional experts and trainers are able to apply the methods of a new management works to improve the quality of education in order to be able to competition in a global education sophisticated, especially in light of the expansion of university education and increasing demand it. In response to the aspirations of the Jordanian society and the emergence of the votes of many intellectual leaders, which calls for the need to develop the education and access to better quality standards, to know the future and security access to the twentieth century, it is important to be detected on the quality of academic programs of universities in Jordan, 
including Al- Balqa' Applied University, to reconsider those programs (inputs, processes and outputs) aims at enhancing their effectiveness, and raise efficiency, develop and improve their components through the vision of the academy future focus primarily on improving the qualitative dimension of the elements of academic programs with a focus on upgrading its outputs.

Therefore many institutions of higher education began in recent years in to design methods and new tools to measure the results and outputs of higher education, in order to reform processes undertaken by the community, and to face the low levels of them because the big challenge for universities of Jordan at the moment is not only to provide education for all citizens, but emphasized on the education should provide high quality, and is planning areas of modern development concept developed rapidly, because the planning processes are constantly looking for more efficiency and innovation in line with the rapid changes and subsequent taking place in the developed world, as it highlights all the philosophies and new theories working to solve organizational problems and the trend towards the application of modern concepts and techniques in our university is very important in order to upgrade them to high levels of performance and efficiency to improve outcomes.

The planning in the in the Jordanian university and specially in including Al- Balqa' Applied University does not have the enough important, as the planning process and the formulation of strategic plans are still placed separately from the indicators and standards of quality academic programs, as noted by researchers that the Jordanian universities develop strategic plans and then put plans for quality improvement programs, which refers to the weakness in the recognition of the importance of strategic planning and integration.

Since the universities of Jordan, including the Al- Balqa' Applied University have serious attempts to improve the performance and simulate their counterparts from Arab and international universities that offered, and made efforts to develop strategies to adopt planning and quality of educational programs in an effort to improve performance and provide input and process models for change towards continuous improvement and efficient performance, therefore the research forward in the way of knowledge of the impact and reality of planning on the quality of educational programs, because Al- Balqa' Applied University and affiliated colleges adopted quality systems input to improve its academic programs, and the desire of them also in upgrading the performance of cadres academic, administrative and technical to provide educational services and educational distinct to all on a high level of quality, taking into account the continued development of these programs, both quantitatively and qualitatively concerning the law of BAU and accreditation standards the public and private sectors with his painting of the goals and objectives of striving through the means and many programs, from this standpoint the problem of the study is to identify the impact of the reality of planning on the quality of educational programs at the Al- Balqa' Applied University.

\section{Hypotheses}

Consistent with the study subject and its problem and to achieve its objectives the following hypotheses were tested:

1) The First Hypothesis (H1): There is a significant correlation statistically between planning and the effectiveness of educational programs and effectiveness at a level significantly $(\mathrm{P}<0.05)$ at Al- Balqa' Applied University.

2) The Second Hypothesis (H2): There is no significant statistically effects of the variables on programs and personal effectiveness at the level of significance $(\mathrm{P}<0.05)$ at Al- Balqa' Applied University.

3) The Third Hypothesis (H3): There is no significant statistically effects of personal variables on educational programs and effectiveness at a level significantly $(\mathrm{P}<0.05)$ at Al- Balqa' Applied University.

4) The Fourth Hypothesis (H4): There is no significant statistically effects of the planning and its effectiveness in the quality and effectiveness of educational programs at the level of significance $(\mathrm{P}<0.05)$ at Al- Balqa' Applied University.

\section{Objective of the Study}

The aim of this study was to identify the impact of the reality of planning on the quality of educational programs at the of Al- Balqa' Applied University from the point of view of faculty members and heads of departments, deans, and detect whether there are differences of statistical significance due to the variables (sex, qualification, years of experience, Job Title)and to make recommendations pushing to improve strategic planning processes and their impact on quality standards for academic programs in the Al- Balqa' Applied University.

\section{The Importance of the Study}

Study derives its importance from the following: 
The importance of the surveyed variables (Planning, Quality), which plays a key role in the university excellence and promote competition and continuity.

1) The application of a field study on the vital sector (higher education institutions - Al- Balqa' Applied University).

2) Conducting the study in an extraordinary time in terms of work to implement the accreditation requirements in the public and private academic year (2014/2015) and the adoption of quality standards and national and classified on the basis of universities.

3) The importance of the study is in the benefit those responsible for strategic planning processes and quality standards for academic programs at Jordanian universities, public and private Al- Balqa' Applied University in order to upgrade them to high levels of performance and quality assurance and raise the efficiency of services provided.

\section{Theoretical Framework}

The concept of quality start in the industry and the economy, it was natural to seep these concepts and ideas from the industry and the economy to the education sector, like many of the concepts and ideas of educational back in its origins to other fields, man is the center thinking and development, which is also the focus of the educational process and the focus of development, midst and has made civilizations, and progressing nations, has become the application of quality in education an urgent demand to interact with all the variables of the age rapidly, and achieve comprehensive sustainable development of society through the development of academic programs, and a system evaluation measures the accurately the extent of students of the information, and achieve outcomes better in the specifications of the graduate, and inclusive education for all members of the community and maintain high rates and ratios leak is low, and the development of techniques used in the completion of the work and provide the best methods that produced research to develop the capacity of the community and its energies and its products (Ahmed,2005).

Hence the quality in the forefront of the vital strategic confronting us in our lives in general, and in the areas of specialties quality, in particular, This is because, as noted by Cheng (2003) to scientific and technical progress successive and increased competition among institutions production and services in the light of the growing supply over demand, and goes beyond the concept of quality means traditional any quality product or service to include the quality of the institution or organization in order to improve and develop processes and performance, reduce costs, and control the time, and achieve customer preferences and market requirements, and teamwork, and the strengthening of belonging. (Mack, 2008).

That the application of quality in the field of university education does not mean planning to make universities commercial enterprises seeking to double their profits by improving their products, but they should benefit from it at the entrance of quality in higher education is to develop a set of standards and procedures aimed at implementing continuous improvement in educational programs to quality, and in order to double the benefit of the primary beneficiary of all educational efforts, a student and community members. (Choon, 2008).

The studies related to this field that the system of quality in higher education is working on the development of all aspects of administrative work and academic at the university level, and thus helps to make a change integrated easily raise efficiency in general, as the development of a part or a particular service and the survival of parts and services as they are hindering or may prevents any application for any partial change. (Mahjoub, 2003).

The application of quality a trend evolutionary presses a framework central role in most of the world in their respective fields today, to evaluate university performance and scalability, due to the crisis experienced by the universities as a result of the weakness of their ability to respond rapidly and successive variables societal and global challenges needed for development, which calls for a change in the way University with the problems of society in check its effectiveness and efficiency. (Hamad, 2008).

The quality of academic programs in all its criteria and indicators based on strategic planning to build founded and core of each of its components of policy planning, systems, and infrastructure development, planning operations, and investment of resources, and the development of human potential and material in order to achieve the objectives of Jordanian universities, and allow them the ability to conduct analysis of regulatory the founders and updated on a regular basis, in order to achieve the overall institutional development within the framework of the flexibility of integrated performance, aiming at the development and continuous improvement. (Albatsh, 2009). 
Whereas university is home base which is developing the science, and discover the knowledge, grow skills, it has recorded most of the institutions of higher education progress in the field of planning strategies in support of the growth and development of education and scientific research in, and paid to improve their performance and achieve quality in their systems, and processes, and outputs special attention, based on the contributions of the pioneers of management, accreditation bodies and quality assurance in determining the quality standards for the performance of higher education institutions such as the accreditation and quality assurance in Jordan, where he began these bodies apply these indicators on the base ensure minimum provide criteria for the granting universities and institutes according to their programs, and the pursuit through dissemination of a culture of excellence to the continuous upgrading of the indicators and identified, according to the reached the modern science of evolution and upgrade. (Ministry of Higher Education and Scientific Research, 2007).

\section{Planning and Quality}

Planning runs to adopt the concept of development aims at the constant improvement in the quality of working life, to ensure participation for all, infrastructure development operations, and to find alternatives and methods based on in-depth understanding of the environment, which reduces the rates of waste resulting from confusion and randomness, and earns those who support it and the participants confidence in themselves and controlling, and represents a motivation and a catalyst towards achieving the objectives of the university. (Hilali, 2006).

Because achieving the goals of quality and the Exclusive Quality in an optimal way, as pointed out by Paris (2003) you need to:

- Many of the statistical data and technological data.

- Analyze the implications of every step of a scientifically accurate analysis.

- The comparison between the results of multiple alternative steps.

- A balance between the requirements of achieving the objectives and the resources available.

The principles and perspectives quality become an actress basis is important in the process of building goals, which is the essence of the planning process, the mouthpiece of the outputs of various stages, and also that the quality management and change management can not be applied in a isolation from the understanding of the objectives and concepts of planning for both concepts of close association successfully quality applications. (Lerner, 1999).

The planning for quality is important in achieving their objectives, and one of the most important components, standards and highlights Kelada (2004) the importance of culture, vision, values and philosophy in the embodiment of the link between planning and quality as key elements and foundations mission is built to identify trends and strategies for the university, and represents a decision which determines the University of wording, the course of action, and the accuracy of its success and its impact on the operating environment in which, if built culture of the employees within the organization have become part of their customs and traditions, and formed their vision and understanding of the future, and expressed the unwritten values. (Alahnasawy, 2006).

When initiation of the planning process to begin diagnosis leading to the preparation of the objectives of quality verification, through the known external environment (clients, the market, the size of the competition), and setting goals that work to attract and satisfy the community beneficiaries, then headed for the analysis of the internal environment concerned with the distribution of materials, development and investment strengths and address the imbalance and thus this analysis is very important for quality purposes. (Sultan, 2006).

The quality objectives are determined after the completion of the diagnostic process and studied carefully, and I've had people featherbed error only, and then emerged the idea of improvement in terms of the initiative, and now there may not be wrong, but the desire to continuous improvement is the dominant feature of the behavior, attitudes and culture institutions, so we find that development of concepts towards improving the work led to the development of strategic plans and alternatives to serve the development of the institution. (Watty, 2005).

Moreover, the process of implementing the goals based on the collective performance, and the interaction of all departments and divisions in achieving the objectives of the university, and this is reflected in the philosophy of quality and principles that focus on participation and considers that the achievement of quality is the participation of all members of the institution and the beneficiaries of their services, and to ensure better results for the process involved in providing the preceded implementation of the verification process everyone's participation in the formulation and development goals of the institution during the planning process. (Aref, 2002).

Because the application of quality is the responsibility of the university administration, as noted Dooris \& Kelley (2004), the University Bound development plan to ensure the good application of the institution as a whole, then the 
plan of activities for each of the sectors within it, so it should be a quality issue for planning and, if considered to the formation of culture and instilling values and drafting philosophy in their theoretical framework, and identify policies stage of pregnancy realize the vision, the planning process is completed with the vision and mature goals that produces quality, quality is if not random does not occur by chance not succeed unless planned carefully. (Doherty, 2008).

\section{Educational Programs}

The university provides educational programs leading to graduate students with efficiency, and provide them with the skills, knowledge and scientific capabilities and research, hence the evaluation of programs, and the continuity of improvement and development, is a constant of the institution, and the development and modification of programs, plans and procedures, resources and components in response to changing circumstances, and the needs of society and its institutions, of in order to maintain educational programs with a high level of quality.

The academic program main axis in the educational process, so it sought the developed countries to give the process of evaluating the quality of the academic program due importance, and put his own standards to adjust education include: design of the program and its objectives, educational material, learning resources, interaction between students and teachers, and evaluating student performance, evaluation the program. (Almusallam, 2011).

The construction of programs or revised many of the important elements such as the selection of content that should be included in the course, and points (Nicholson, 2011) to the problem of building programs and determine its contents related to a set of variables and the increasingly intertwined in grades higher, because the event is about the lack of visions value and future resources, which will reflect negatively on the formulation of precise targets educational, and sees (Tuck, 2011) that the number of academic programs and approved by the higher education institutions and reviewed part of the quality assurance processes that seek institutions to confirm it, should also take into account the program meet the criteria academy, the specific criteria set by the specialized advisory committees include a minimum of knowledge and skills acquired supposed to graduates of the program and achieve the mission and objectives of the organization. (Saudi National Commission for Academic Accreditation and Assessment, 2008).

Starting building programs many procedures carried out by departments and colleges and scientific management in the enterprise, and can be summarized as the most important requirements for the construction of new programs (Accreditation Body and Ensure the Quality of Higher Education Institutions, 2011) as follows:

- The context of the program includes general information about the university, and a comprehensive study of the program shows the message and the overall objective and sub-goals.

- Study Plan for the program and learning outcomes.

- Curriculum and teaching methods and means of evaluation.

- Human resources and qualifications available.

- Financial resources and facilities (halls, the library, and related laboratories).

The competent departments at the university in cases of adoption of the program or update send it to the Ministry of Higher Education according to the model specified addresses a number of elements that represent academic standards task such as curriculum and learning outcomes that the program seeks to achieve, and the system of student assessment, methods and sources of learning, evaluation and revision.

The educational program should be a that has a clear message, certified postings reflect the vision and message includes clear objectives, measurable and investigation regarding its role and activities in the most important good practices that should be the tutorial to be taken in this regard, as referred to by the (National Center for Quality Assurance and the Adoption of Educational Institutions,2012) as follows:

- The existence of the vision, mission and goals.

- The existence of appropriate processes for the development of mission and goals.

- Use the message and objectives in the planning of activities and processes.

- There is a clear relationship between the message and goals.

- The program that uses the letter as a basis for planning and evaluation of its activities and operations.

- The program coordinator is chosen (section or division) based on the specific terms of reference and within the regulations. 
- prefers to encourage the teaching methods applied strategy stemming from education and faculty members, and students among them.

- must take into account the appropriate program management programs to the needs of the community and the money market.

- The program has self-learning areas.

\section{Previous Studies}

The researchers access to some of the previous studies on the subject of the study, namely:

(Abu al-Rub, 2010), conducted a study aimed to statement the relationship between quality management and strategic management, which has been used the descriptive analytical method, and used the resolution as a tool and found that the activation of quality management in the Arab universities need to integrate with the process of strategic management and requires that the conceptualization of the University based on systems theory, and convinced senior management and awareness of the concepts of quality management, and the adoption of a model for quality management is applied in the light of the matrix specific to ensure feedback between the dimensions of the system and continuous updating, and practice of strategic management, which includes a diagnosis of reality and identify the strengths and weaknesses enabling continuous process improvement, and integration between quality management and strategic management.

Gallagher (2007) conducted a study at the University of California for improving the effectiveness and quality of the organization through the statement of the relationship between academic programs and strategic planning that focuses on identifying mission of the university and its objectives and steps of the application of strategic planning, the study showed the importance of strategic planning in the preparation of plans, which is working to develop university systems and lead to the development of learning outcomes by enhancing the skills and abilities of students performed, and the study showed the importance of working through the practice of strategic planning in determining academic programs and study recommended the establishment of a system for assessing student learning and the development of policies and practices in order to achieve strong leadership aimed at improving the quality and effectiveness of the university.

Westefiek \& Backmon, (2007) conducted a study aimed to the need for the existence of plans, strategies and clear the academic programs of accounting, especially wishing to obtain accreditation from international donors to him, and led the American Association of Colleges and Schools and business schools, which emphasizes the need for variation in the characteristics and qualities of the faculty to those programs, in terms of the variables of sex, race, and a statement on the quality and health of the work environment academic those programs, which should highlight accounting software, wishing to obtain accreditation, a link is clear between the mission and objectives of those programs and the existence variation in the characteristics and qualities of whole faculty working with those programs, with the need to also impact the existence of such diversity on the quality of the work environment academic those programs, the study found a range of results was the most important are: the existence of diversity in the faculty of accounting in terms of gender and race will be accounting programs useful when formulating its mission and objectives, and thus assist in the planning to make the changes required in order to qualify for accreditation.

In a study conducted by the Baldrige National Quality Program (2005) which aimed to develop education standards for academic programs, to make the changes and amendments to the program to determine the strengths of the organization and consistency in style, distribution, and integration between items, and identify regulatory gaps, and use the descriptive analytical approach. The findings of the study, changes that included every item of leadership, strategic planning, knowledge management, operations management and the results of institutional performance, where he became the focus and clear about the responsibility of leadership in guiding the organization and supervision, has been a focus on strategic planning towards the implementation of the plans, and knowledge management must to rely on the review of organizational performance, and operations management has become focused on operational planning to ensure the availability of financial resources and allocations and the continuation of operations in times of emergency, and the results became focused on performance results related to effective leadership.

Aljondi (1999) conducted a study aimed to know the method of strategic planning and the potential benefit from the upgrading of the quality of educational systems, the study adopted a descriptive approach and style, the concept of strategic planning, according to the analytical approach reveals its objectives, and the problems of its application and the necessary ingredients for its effectiveness when used in the field Education, The study concluded a set of results, 
including: strategic planning provides educational institutions thought the main help to identify the core issues faced by, and then guide them to make rational decisions rationally, and helps strategic planning guidance and integration of administrative activities and the executive, the relationship between productivity and returns be clarified through planning and through the guidance of individuals within the organization.

Kilani (1998) used the approach the qualitative research and aimed to develop a plan designed to bring about a change in educational administration towards quality management so that the balance of those between planning processes and quality, through a preliminary stage know the culture of quality management philosophy and procedures lead to the commitment involved in the change, The stage needs assessment and a system priorities according to the system Kaufman, who analyzes the administration by the entrance systems, phase control and the statement of value added, and the researcher recommended the adoption of the plan, and the introduction of total quality management in the field of education with be without prejudice to the culture of the society and the foundations of education in it.

Finally, the study by Khafaji and Baiarman (1995), which aimed to expand the philosophy of quality management to reflect the time dimension strategic performance of the institution as a whole through the link between quality and planning and the integration of strategic quality components and objectives of strategic planning, and researchers used the descriptive analysis in addition to the curriculum Relational, the study found the following results: The development of strategic planning for universities requires the integration strategy overall quality with the components of the strategic plan and the development of mission of the university requires included providing educational programs high enjoyed a high level of quality and provide a service beneficiaries and to encourage research and community service and the opportunity to share best students and faculty members teaching, and develop the goals and objectives of the university requires improving the quality of academic and professional preparation of students, and contribute to the process of assessing policies and procedures for planning to know the trends of Interior and better analysis of the internal environment, the study found in the implementation of the strategic plan to segmentation strategies, plans and budgets of medium-and short-term, the development of the operational programs detailed necessary.

\section{Method and Procedures}

\subsection{Instrument of the Study}

The researchers developed a questionnaire based on accreditation standards and quality accredited by the Accreditation Commission of Higher Education as a tool to collect data and information to know the views of academics, faculty members and some of them occupy managerial positions in colleges on the subject (and the reality of planning at the university and its impact on the quality of educational programs), through (9) paragraphs to measure the independent variable (planning) and (17) paragraph to measure the dependent variable (the quality of educational programs). Likert scale has been using to determine the weights of paragraphs devoted to measure, which is (totally agree, agree, agree somewhat, not I agree, do not completely agree) that following digitally degrees represent $(1,2,3,4,5)$.

\subsection{Veracity of the Instrument}

To verify the veracity of the tool if able to measure really, which is developed to measure variables, the researchers view it in its initial group of arbitrators to ascertain the extent of affiliation paragraphs to the fields and make sure drafting language and how it fits with the accreditation standards and quality of these aspects, was keen Researchers presented to the three principals in the development unit and quality assurance at the University Centre for comments on the questionnaire, where they were taking the observations and opinions of teachers was conducted arbitrators required amendment.

\subsection{The Reliability of the Instrument}

Reliability of the instrument was extracted reliability coefficient according to the equation Cronbach's Alpha to ensure the internal consistency of variables based on the answers of the respondents reconnaissance, were also extracted reliability coefficient according to Cronbach's Alpha after the application of the study to all members of the study population, and Table 1 illustrates the value of reliability coefficient.

Table 1. Cronbach's alpha coefficients to test the reliability instrument of the study

\begin{tabular}{cc}
\hline Dimension & Cronbach's Alpha Coefficient \\
\hline Planning And Effectiveness & 0.82 \\
Quality And Effectiveness Of Educational Programs & 0.88 \\
\hline
\end{tabular}


Notes from the Cronbach's alpha values in Table 1 that the reliability coefficients for fields of study a high proportion of high fastness and acceptable for the purposes of the study.

\subsection{The Study Population and Sample}

The community of the study is defined by the Al- Balqa' Applied University which is the second largest university in Jordan, it was founded in 1997 and now it includes six colleges in the center and (12) college spread over all the regions in Jordan, and give several degrees except for a doctorate degree in many disciplines humanitarian and practical, it include (1382) works all of them are operating employee, administrative, and academic: (Dean, Vice Dean, Assistant Dean, Head of Department, Vice President, Director of the administrative unit), (586) questionnaire have been distributed randomly for the sample of (9) colleges works (661) to faculty member, (248) were questionnaire recovered and the valid for analysis were (37.51\%) for the number of faculty members at colleges and nine of (17.94) for all faculty members at the university and (42.32\%) for a number of questionnaires distributed, as shown in Table 2 as follows:

Table 2. Community and study sample

\begin{tabular}{rllll}
\hline College & $\begin{array}{l}\text { Faculty } \\
\text { members }\end{array}$ & $\begin{array}{l}\text { Distributed } \\
\text { questionnaires }\end{array}$ & $\begin{array}{l}\text { Recovered } \\
\text { questionnaires }\end{array}$ & percentage \\
\hline Planning and Management & $\mathbf{8 6}$ & $\mathbf{1 0 0}$ & $\mathbf{4 2}$ & $\mathbf{2 7 . 9 \%}$ \\
Salt College of Human Sciences & $\mathbf{6 4}$ & $\mathbf{7 0}$ & $\mathbf{3 2}$ & $\mathbf{5 0 \%}$ \\
College $\quad$ of Agriculture & $\mathbf{3 5}$ & $\mathbf{3 6}$ & $\mathbf{2 0}$ & $\mathbf{5 7 . 1 4 \%}$ \\
$\begin{array}{r}\text { technological } \\
\text { College of Engineering }\end{array}$ & $\mathbf{3 7}$ & $\mathbf{4 0}$ & $\mathbf{2 4}$ & $\mathbf{6 4 . 8 6 \%}$ \\
Princess Alia University College & $\mathbf{1 5 0}$ & $\mathbf{1 0 0}$ & $\mathbf{5 5}$ & $\mathbf{3 6 . 6 6 \%}$ \\
Princess Rahma University & $\mathbf{5 5}$ & $\mathbf{6 0}$ & $\mathbf{1 8}$ & $\mathbf{3 2 . 7 2 \%}$ \\
College & & & $\mathbf{2 9}$ & $\mathbf{3 4 . 9 3 \%}$ \\
Amman University College & $\mathbf{8 3}$ & $\mathbf{6 5}$ & $\mathbf{1 2}$ & $\mathbf{1 3 . 3 3 \%}$ \\
Zarqa University College & $\mathbf{9 0}$ & $\mathbf{7 0}$ & $\mathbf{1 6}$ & $\mathbf{2 6 . 2 2 \%}$ \\
\hline Karak University College & $\mathbf{6 1}$ & $\mathbf{4 5}$ & $\mathbf{2 4 8}$ & $\mathbf{3 7 . 5 1 \%}$ \\
\hline Total & $\mathbf{6 6 1}$ & $\mathbf{5 8 6}$ &
\end{tabular}

Table 3 shows that the calculated average for the a agreeing sample members for the study dimension, the "planning" have (2.67) where the "quality" have $(2,64)$.

Table 3. Averages and standard deviations for fields of study

\begin{tabular}{lrrrrr}
\hline Dimension & \multicolumn{2}{c}{$\begin{array}{l}\text { Arithmetic } \\
\text { Average }\end{array}$} & $\begin{array}{l}\text { Standard } \\
\text { Deviation }\end{array}$ & Percentage & Degree \\
\hline $\begin{array}{l}\text { Planning and Effectiveness } \\
\text { Quality and Effectiveness }\end{array}$ & of & 2.67 & 0.729 & 53.40 & Medium \\
Educational Programs & & 2.64 & 0.676 & 52.80 & Medium \\
\hline
\end{tabular}

10.5 Hypotheses Test

The first hypothesis (H1): There is no significant statistically correlation between the planning and the dependent variable the educational programs at the level of $(0.05 \leq \alpha)$ at Al- Balqa' Applied University.

To test the first hypothesis, the researchers using the Pearson Test correlation ,the value of Pearson correlation coefficient was (0.707), a coefficient is statistically significant at the level of significance less than (0.05), leading us to accept the hypothesis which states: There is a significant statistically correlation between the planning and the dependent variable the educational programs.

The second hypothesis $(\mathrm{H} 2)$ : There is a significant statistically effects of the demographic variables on planning at $(0.05 \leq \alpha)$ in Al- Balqa' Applied University.

The first sub-hypothesis of the second hypothesis: There is a significant statistically effect for the sex on planning and its effectiveness at $(0.05 \leq \alpha)$ in Al- Balqa' Applied University. Table 4 show the test of the first sub-study of the second hypothesis. 
Table 4. The second sub- hypothesis (T) test

\begin{tabular}{lrrlrrr}
\hline T & df & Significant & Sex & Number & \multicolumn{1}{c}{ Mean } & \multicolumn{2}{c}{ Standard Deviation } \\
\hline \multirow{2}{*}{-1.645} & \multirow{2}{*}{246} & \multirow{2}{*}{0.101} & Male & 174 & 2.62 & 0.690 \\
& & & Female & 74 & 2.79 & 0.809 \\
\hline
\end{tabular}

Table 7 the value the level of significance was greater than $(a=0.05)$, which leads us to accept the hypothesis the first sub-hypothesis of the second hypothesis: There is a significant statistically effect for the sex on planning and its effectiveness at $(0.05 \leq \alpha)$ in Al- Balqa' Applied University.

Second sub-hypothesis of the second hypothesis (H3): There is a statistically significant effect of age on the planning at the level of significance $(0.05 \leq \alpha)$ in Al- Balqa' Applied University.

To test the hypothesis the ANOVA test has been used, Table 5 shows that:

Table 5. ANOVA results for the second sub-test: the hypothesis of the second hypothesis (H2)

\begin{tabular}{|c|c|c|c|c|c|}
\hline & Sum Of Squares & df & Square Means & $\mathbf{F}$ & Significant \\
\hline $\begin{array}{l}\text { Between } \\
\text { Groups }\end{array}$ & 6.605 & 3 & 2.202 & 4.298 & $* 0.006$ \\
\hline Within Groups & 124.997 & 244 & 0.512 & & \\
\hline Total & 131.602 & 247 & & & \\
\hline
\end{tabular}

Through the Table 5 we note the value (F) was statistically significant at the level of significance is less than (0.05), leading us to accept the hypothesis argument: There is a statistically significant effect of age on the planning at the level of significance $(0.05 \leq \alpha)$ in Al- Balqa' Applied University.

Table 6. Results of the Scheffe' Test for the difference for the effect of age on planning

\begin{tabular}{ccc}
\hline Age (I) & Age(J) & Mean Difference (I-J) \\
\hline $24-35$ & $36-44$ & $.3407\left(^{*}\right)$
\end{tabular}

Table 6 Show We note that the differences in the views of the members of the study sample according to the age variable was among those between the ages of (24-35) and ranging between (36-44) for the benefit of the aged (24-35 years old).

The third sub-hypothesis from the third hypothesis (H3): There is a statistically significant effect of scientific qualification on planning and effectiveness at the level of significance $(0.05 \leq \mathrm{R})$ in Al- Balqa' Applied University.

Table 7. ANOVA results for the third sub-hypothesis from the third hypothesis (H3)

\begin{tabular}{|c|c|c|c|c|c|}
\hline & Sum Of Squares & df & Square Means & $\mathbf{F}$ & Significant \\
\hline $\begin{array}{l}\text { Between } \\
\text { Groups }\end{array}$ & 4.134 & 3 & 1.378 & 2.638 & 0.052 \\
\hline Within Groups & 127.468 & 244 & 0.522 & & \\
\hline Total & 131.602 & 247 & & & \\
\hline
\end{tabular}

Through the Table 7 we note the value (F) was statistically significant at the level of significance is less than (0.05), leading us to accept the hypothesis argument: There is a statistically significant effect of scientific qualification on planning and effectiveness at the level of significance $(0.05 \leq \alpha)$ in Al- Balqa' Applied University.

Table 8. Results of the Scheffe' Test for the difference for the scientific qualification on planning and effectiveness

\begin{tabular}{ccc}
\hline Scientific Qualification (I) & Scientific Qualification (J) & Mean Difference (I-J) \\
\hline $\mathrm{PhD}$ & Master & $-.3172\left(^{*}\right)$
\end{tabular}

Through the Table 8 we note that the differences in the views of the members of the study sample variable depending on the qualification were those with a Ph.D.s have more differences than those a Masters degrees .

Fourth hypothesis (H4): There is a significant statistical effects of the effectiveness of planning effectiveness in the quality on the effectiveness of educational programs at the level of significance $(0.05 \leq p)$ in Al- Balqa' Applied University.

The study to test the hypothesis fourth test has been used regression analysis, and the controversy (31): 
Table 9. Regression analysis to test the effects of the effectiveness of planning effectiveness in the quality on the effectiveness of educational programs

\begin{tabular}{lll}
\hline & B & T \\
\hline Planning Effectiveness & 0.042 & 15.688 \\
f & 246.125 & \\
r2 & 0.5 & \\
Sig. & $0.000^{*}$ & \\
\hline
\end{tabular}

The Table 8 that the planning and effectiveness has a significant effect on the quality and effectiveness of educational programs and shows that by the value of $\mathrm{F}$ amounting (246.125) at the 0.05 level, which also, the results also show that $50 \%$ of the variations occurring in the quality and effectiveness of educational programs dating back to the planning and effectiveness.

Which leads us to accept the hypothesis which states: There is a significant statistical effects of the effectiveness of planning effectiveness in the quality on the effectiveness of educational programs at the level of significance $(0.05 \leq$ p) in Al- Balqa' Applied University.

\section{Results}

Based on the analysis of data the study found the following results:

1) The study sample expressed their approval of the moderately areas of study, where the overall rate of the reality of planning (2.67) which is $(53.40 \%)$, and the quality of educational programs averaged total (2.64) which is $(52.80 \%)$.

2) The study showed a correlation significant statistically correlation between the planning and the effectiveness and quality of educational programs in Al- Balqa' Applied University, where the value of Pearson's correlation coefficient (0.707) at the 0.05 level of significance.

3) The study showed the effect of some personal variables for the study sample (age, qualification, years of experience) on the planning and effectiveness, where the values of (f) of these variables in the order (4.298) (2.638) (3.173), and the lack of effect of variables (Gender, Job Title) on the planning and effectiveness, where the value of the level of significance for them (0.101) (0.129), respectively. This is due to the occurrence of most samples within one age group (24 - 35 years) and doctoral degree campaign and the number of years of experience medium and short, and they acknowledge the existence of planning with the application's lack of commitment to be an effective.

4) The effect also appeared for personal variables (age, educational qualification, and years of experience) on the quality of educational programs and evaluation, where the values of (f) of these variables, respectively, are: (5.04) (3.245) (4.125). Did not show the effect of the variables (sex, functional level) on the quality of educational programs, reaching levels of significance: (0.244) (0.477), respectively.

5) The study showed that the planning and the level of effectiveness has an impact on the quality of educational programs in Balqa Applied University, as the value of (f) (246.125) at the 0.05 level, and (50\%) of the differences occurring in the quality of educational programs and their effectiveness back to the planning and applied effectively.

\section{Conclusions and Recommendations}

Study concludes that the quality of educational programs related to proper planning and follow-up implementation plans within the range specified time and reviewed according to developments different, especially related to the labor market, to ensure supplying various sectors elements of qualified human resources, but the reality of planning at the University of modest where the overall rate him (2.67), from where the development of plans and applied and reviewed to contribute to the existence of educational programs are successful, where the study showed that $50 \%$ of the differences occurring in the quality of educational programs dating back to the planning and applications, in addition to the effect of some personal factors (age, qualification, years of experience) to plan because of the perception and conviction of the importance of planning and the feasibility of it, where the study showed that age group (24 - 35) and the campaign doctoral degree and experienced medium more knowledgeable and aware of the reality of planning at the university, in terms of the development of plans and their importance and the commitment of senior management backing and implementation, and these are the cadres installed at the university of the presidency the university and some deputies are appointed by the President and they cadres to other universities. 
The study recommends the spreading the culture of planning and support of senior management at the university have put the ambitious plans that represent the vision and fulfilling its mission as a participatory between everyone when developed and implemented, and not to keep these plans locked drawers offices, making it possible to develop educational programs according to the need of the local labor market and regional levels, and work on the review as an ongoing process, and work on the review as an ongoing process, and that all but the management of the university by members of young children on the basis of objective and not from other universities come to the university as a way station in charge on the basis of non-objective.

\section{References}

Abu Al-Rub, Imad. (2010). The Relationship between Quality Management and Strategic Management Quality Assurance in Higher Education Institutions, research and studies. Amman: Dar al-Safaa for publication and distribution.

Accreditation Commission and ensure the Quality of Higher Education Institutions. (2011). Manual of Institutions of Higher Education, and the Ministry of Higher Education and Scientific Research: Oman.

Ahmed, Ahmed. (2005). The Overall Quality in Educational Administration And School, Dar fulfill: Alexandria.

Albahnasawy, Fardous. (2006). The System of Higher Education in the United States of America, the world of books: Cairo.

Albatsh, Mohammed. (2009). The Jordanian Experience in the Field of Accreditation and Quality Assurance, and a working paper submitted to the Higher Education Quality Symposium: Tripoli.

Aljondi, Aldel Alsaed. (2009). Strategic Planning and Its Role in Improving the Adequacy and Effectiveness of Educational Systems. The future of the Arab Education Journal, 16(17), 37-75.

Almusallam, Abdullah. (2007). Higher Education Accreditation and Quality Assurance in the Kingdom of Saudi Arabia. Proceedings of the First National Conference for Quality in Higher Education, Riyadh, Saudi Arabia, pp. 112-119.

Anderson, Gina. (2006). Assuring quality, Resisting Quality Assurance: Academics: Responses to Quality in Some Australian Universities. Quality in Higher Education, 2(12), 77-88.

Arif, Nadia. (2002). Strategic Planning and Globalization. University House: Cairo.

Baldrige National Quality Program. (2005). Education Criteria for Performance Excellence, U.S.A. Retrieved from http://baldrige.nist.gov/PDF_files/2005_Education_Criteria.pdf

Challagher, E.R. (2007). The Relafion ship between assessing student learning out comes and strate Gic planning in California Community college. An unpublished Doctoral Dissertation Claremont, California.

Cheng, Y. (2003). Quality Assurance in Education, Internal inference and Future. Journal of Quality in Education, 4(11), 202-243. http://dx.doi.org/10.1108/09684880310501386

Choon, F.R. (2008). Quality Assurance in Education: An International perspective. Reports- Research, 2(16), 126-137.

Doherty, G. (2008). On Quality in Education. Quality Assurance in Education, 16(3), 255-265. http://dx.doi.org/10.1108/09684880810886268

Dooris, M., \& Kelley, J. (2004). Successful Strategic Planning. Wiley Planning, Wiley Periodicals, Inc, A Wiley Company.

Hamad, Said Salim. (2008). The Overall Quality in Arab Universities. library of Alshiqari, Riyadh.

Hilali, Hilali-Sherbini. (2006). Strategic Planning and Dynamic Change in Educational Systems. The Egyptian Library for publication: Cairo.

Kelada, Joseph. (2004). Re-Engineering Integration with Total Quality Management, Translation of Srour ( $1^{\text {st }}$ ed.). Dar Mars: Riyadh.

Khafaji, Abbas Baiarman, Jerry. (1995). Strategic Planning and Total Quality Management in Academic Institutions. Journal of Banking and Financial Studies, 1(3), 87-95.

Kilani, Anmar. (1998). Planning For Change through Total Quality Management in the Field of Educational Administration. Research published in the Conference about teach Arabic privileged to meet the challenges of renewable, Faculty of Education, Helwan University, Egypt, pp. 321-341. 
Lerner, A. (1999). A Strategic Planning Primer for Higher Education. Research Associate, College of Business Administration and Education, California State University, Norhridge.

Mace, J. (2008). Higher Education and Business. Higher Education Review, 7(25), 68-72.

Mahjoub, Basman. (2003). The Department of Arab Universities in the Light of International Standards - An Empirical Study of the Faculties of Science, administrative and trade. The Arab Organization for Administrative Development: Cairo.

National Center for Quality Assurance and Accreditation of educational institutions. (2012). Guide for Quality Assurance and Accreditation of institutions of higher education, Cairo.

Nicholson, K. (2011). Quality Assurance In Higher Education: A Review of Literature. Unpublished manuscript, Council of Ontario Universities Degree Level Expectations Project McMaster University, Hamilton, Canada.

Paris, K. (2003). Strategic Planning In the University, Consultant Office of Quality Improvement. University of Wisconsin System Board of Regents-Madison.

Qowi, Bouhnah. (2008). Higher Education in the international environment contemporary: An approach through the entrance of quality. Paper presented at the Second Conference of the planning and development of education and scientific research in the Arab countries (towards building a knowledge society), King Fahd University of Petroleum and recycled, Dhahran.

Saudi National Commission for Academic Accreditation and Assessment. (2008). accreditation standards and quality assurance in higher education institutions. Riyadh.

Sultan, Khaled. (2006). Strategic Thinking And Planning In Higher Education Institutions, and the working paper submitted by the Forum administrative and fourth of the Saudi Management Association, March, Saudi Arabia.

Taylor, W., \& Cleland D. (2004). Strategic Planning and Management Handbook, Newyork: Van Nostrand Reinhold Company.

The Arabic Network for Quality Assurance in Higher Education. (2012). A glossary of terms Quality Assurance in Higher Education. Cairo.

The Jordanian Ministry of Higher Education. (2007). The National Strategy for Higher Education and Scientific Research, 2007-2009. Amman.

Tuck, C. (2011). The European Quality Assurance Register for Higher Education and its Role European Higher Education. Paper Presented at the CHEA International Seminar, Washington, D.C.

Watty, K. (2005). Quality in Accounting Education: What Say the Academics? Quality Assurance in Education, 2(13), 120-132.

Weisenfeld, L. W., \& Backmon, B. (2007). Accounting Faculty Perceptions Environment Diversity Issues and Academic Environment. Issues in Accounting Education, 2(22), 429 -445.

Wilkinson, R., \& Taylor, J. (2007). A Practical Guide to Stratagic Enrollment Management Plaanning in Higher Education. Educational Policy Institute. 